\title{
Net ecosystem exchange of carbon dioxide and water of far eastern Siberian Larch (Larix cajanderii) on permafrost
}

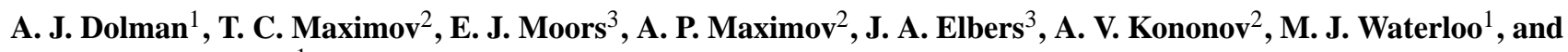 \\ M. K. van der Molen ${ }^{1}$ \\ ${ }^{1}$ Vrije Universiteit, Dept. Hydrology and Geo-Environmental Sciences, Faculty of Earth and Life Sciences, De Boelelaan \\ 1085, 1081 HV Amsterdam, The Netherlands \\ ${ }^{2}$ Institute for Biological Problems of the Cryolithozone (IBPC), Yakutsk, Republic of Sakha (Yakutia), Russia \\ ${ }^{3}$ Alterra, PO Box 47, 6700 AA Wageningen, The Netherlands
}

Received: 24 June 2004 - Published in Biogeosciences Discussions: 6 August 2004

Revised: 16 November 2004 - Accepted: 1 December 2004 - Published: 23 December 2004

\begin{abstract}
Observations of the net ecosystem exchange of water and $\mathrm{CO}_{2}$ were made during two seasons in 2000 and 2001 above a Larch forest in Far East Siberia (Yakutsk). The measurements were obtained by eddy correlation. There is a very sharply pronounced growing season of 100 days when the forest is leaved. Maximum half hourly uptake rates are $18 \mu \mathrm{mol} \mathrm{m}^{-2} \mathrm{~s}^{-1}$; maximum respiration rates are $5 \mu \mathrm{mol} \mathrm{m}^{-2} \mathrm{~s}^{-1}$. Net annual sequestration of carbon was estimated at $160 \mathrm{gCm}^{-2}$ in 2001 . Applying no correction for low friction velocities added $60 \mathrm{~g} \mathrm{C} \mathrm{m}^{-2}$. The net carbon exchange of the forest was extremely sensitive to small changes in weather that may switch the forest easily from a sink to a source, even in summer. June was the month with highest uptake in 2001.
\end{abstract}

The average evaporation rate of the forest approached $1.46 \mathrm{~mm} \mathrm{day}^{-1}$ during the growing season, with peak values of $3 \mathrm{~mm} \mathrm{day}^{-1}$ with an estimated annual evaporation of $213 \mathrm{~mm}$, closely approaching the average annual rainfall amount. 2001 was a drier year than 2000 and this is reflected in lower evaporation rates in 2001 than in 2000.

The surface conductance of the forest shows a marked response to increasing atmospheric humidity deficits. This affects the $\mathrm{CO}_{2}$ uptake and evaporation in a different manner, with the $\mathrm{CO}_{2}$ uptake being more affected. There appears to be no change in the relation between surface conductance and net ecosystem uptake normalized by the atmospheric humidity deficit at the monthly time scale. The response to atmospheric humidity deficit is an efficient mechanism to prevent severe water loss during the short intense growing season. The associated cost to the sequestration of carbon may be another explanation for the slow growth of these forests in this environment.

Correspondence to: A. J. Dolman

(han.dolman@geo.falw.vu.nl)

\section{Introduction}

There is increasing evidence that the northern latitudes are experiencing the effects of global warming. The increased and early greening of the land surface as detected by satellite remote sensing and forest inventory data (Buermann et al., 2003 ) is one of the strong lines of evidence. There is also evidence, both from inverse and bottom up modelling studies (e.g. Bousquet et al., 1999; Lucht et al., 2002) that the northern hemisphere is sequestering large amounts of carbon at increased rates. It is thus of considerable interest to determine the carbon uptake of forest in the northern hemisphere. Although Siberian forests constitute $20 \%$ of the world's forest area, little is known about their role in the carbon budget and about their role in the regional and continental water balance.

Preliminary studies using eddy correlation, mostly from Central Siberia, indicate that the sink strength of Siberian pine forest is between 50 and $250 \mathrm{~g} \mathrm{C} \mathrm{m}^{-2} \mathrm{yr}^{-1}$ (Schulze et al., 1999). Estimates using inverse atmospheric modelling techniques suggest a carbon sink capacity of $1.5 \mathrm{Pg} \mathrm{C} \mathrm{yr}^{-1}$ for North Asia (Bousquet et al., 1999). The latter estimate includes all land use change in a ten-year period and is based on atmospheric $\mathrm{CO}_{2}$ measurements. More recently Roedenbeck et al. (2003) suggest an approximately neutral carbon balance for boreal Eurasia. These results obtained using inverse modelling techniques are poorly constrained by the observations and, clearly, more information on the carbon balance of boreal Eurasian forests is needed to better define the a-priori estimates that are used in the inversion studies.

The forests of Siberia represent one of the last natural frontiers in the world. Nearly $65 \%$ of these forests grow in areas with permafrost (Shvidenko and Nilsson, 1994). The Siberian forests in the Far East cover $45 \%$ of the total forests in Siberia. It is estimated that $74 \mathrm{Pg} \mathrm{C}$ and $249 \mathrm{Pg} \mathrm{C}$ is stored in the vegetation and soil, respectively, of forest ecosystems of Siberia (Dixon et al., 1994). The estimated carbon

(C) 2004 Author(s). This work is licensed under a Creative Commons License. 
stocks in the soils of forest and tundra ecosystems of Yakutia amount to $17 \mathrm{Pg}$ under the forests cover (in total 125.5 Mha forest and 37 Mha tundra). This is about $25 \%$ of the total carbon stocks of forest soils in the Russian Federation.

Maximum half hourly rates of Net Ecosystem Exchange of $\mathrm{CO}_{2}$ (NEE) quoted by Röser et al. (2002) for West Siberian Betula and two mixed stands are 13, 10 and $8 \mu \mathrm{mol} \mathrm{C} \mathrm{m}^{-2} \mathrm{~s}^{-1}$, respectively. For the same forest as discussed in this paper, Hiyama (2000) quotes maximum uptake rates for July of $15.9 \mu \mathrm{mol} \mathrm{m}^{-2} \mathrm{~s}^{-1}$. Schulze et al. (1999) quote maximum daytime values in July between 7 and $11 \mu \mathrm{mol} \mathrm{C} \mathrm{m}{ }^{-2} \mathrm{~s}^{-1}$, again for Central Siberian forests. Although it is difficult to precisely compare these rather subjective maximum rates, they do give a qualitative feeling for the magnitude of the flux of Siberian forests.

At present there is little empirical understanding of the role of this stock in the global carbon cycle, or, perhaps more importantly, how it may change in the future under changing natural (fire, climate) or anthropogenic forcing (logging). It is well known (e.g. Lindroth et al., 1998) that European boreal forest on drained peat soils can be large sources rather than sinks of $\mathrm{CO}_{2}$ in years when early thawing sets in. If global warming in the boreal forest region of Eurasia becomes persistent, as suggested by Serreze et al. (2000), then the Eurasian forest on permafrost may experience a similar shift from an arguably small sink to a much larger source. The sheer magnitude of the area involved makes this an important issue for research. The key to understanding this behaviour is to investigate the sensitivity of Net Ecosystem Exchange (the balance between assimilation, and heterotrophic and autotrophic respiration, NEE) in situ. Ideally this would be augmented by longer-term estimates of disturbance such as fires, to assess the Net Biome Production (NBP) (e.g. Körner, 2003; Dolman et al., 2003), but a process understanding at annual timescales is an obvious prerequisite. Thus, to be able to give reliable estimates of carbon sequestration of Far East Siberian forests direct measurements of the net uptake of $\mathrm{CO}_{2}$ at seasonal to annual timescales are required. An advantage of such direct measurements is that they also give insight into the sensitivity of the eco-physiology of Siberian forest to changes in climate. We purposely investigate in this paper the fluxes of both carbon and water, as they are closely interlinked and understanding $\mathrm{CO}_{2}$ uptake by forests requires above all a good understanding of the use of water by the forest.

There has been some scattered previous work on evaporation in this area of Siberia that, amongst others, stimulated the current study. Kelliher et al. (1997) took a series of 9 days of eddy correlation measurements above a forest some $160 \mathrm{~km}$ South of Yakutsk and found average daily evaporation to be at $1.9 \mathrm{~mm}( \pm 0.3)$. Ohta et al. (2001) took a full year of measurements and observed maximum evaporation rates of $2.9 \mathrm{~mm} \mathrm{day}^{-1}$ at the beginning of July. The average rate over the growing season was estimated at $1.2 \mathrm{~mm}$ day $^{-1}$. Ohta et al. (2001) also found a strong seasonality in the evap- oration fluxes that was, not unexpectedly, related to the existence of needles on the canopy. Based on their respective measurements and some interpolation, Kelliher et al. (1997) and Ohta et al. (2001) estimated total annual evaporation of East Siberian Larch to be at 169 and $151 \mathrm{~mm}$, respectively. With an annual precipitation of $213 \mathrm{~mm}$, this leaves preciously little water available for runoff.

For Central Siberian forest Schulze et al. (1999) in an extensive review, quote daily evaporation rates for a larch and two pine forests of 1.4 to $1.7 \mathrm{~mm}$ in July that appear to be somewhat lower that those for East Siberian larch. An analysis of two years of measurements over a Central Siberian pine forest by Tchebakova et al. (2002) found evaporation rates of 1.5 to $2 \mathrm{~mm} \mathrm{day}^{-1}$ with a three year average for the growing season of $1.5 \mathrm{~mm} \mathrm{day}^{-1}$. Generally these low evaporation rates, typically using up to only $20 \%$ of the available energy, are associated with high Bowen ratios, well above 1, even when the forest are well supplied with water.

The little information available today about Siberian forest relates primarily to Central Siberia or concerns relatively short periods of campaign based measurements (see also Heimann, 2002). This paper aims to extend that information and describes direct measurements of net ecosystem exchange of $\mathrm{CO}_{2}$ and water and energy fluxes of a larch forest (Larix cajanderii) in East Siberia, near Yakutsk. This part of the forest may be considered representative of the vast expanse of larch forest of East Siberia.

We present the first series of coupled evaporation and $\mathrm{CO}_{2}$ exchange observations obtained in a two-year period. This allows also within specific uncertainty ranges, the annual sink strength to be determined.

\section{Site description and methods}

\subsection{Site description}

The forests around Yakutsk form part of the vast watershed of the River Lena with an estimated surface area of $2490 \mathrm{~km}^{2}$. The territory of the Sakha Republic (Yakutia) covers some $3.1 \times 10^{6} \mathrm{~km}^{2}$, including the New Siberian Islands. The largest rivers are the Lena, Anabar, Olenek, Yana, Indigirka and the Kolyma. Most of this territory is covered by forest; toward the north the forest changes into tundra lands. A useful, up to date review of the geology, climate and ecology may be found in Giorgiadi and Fukushima (1999).

The measurement site is located in the middle reaches of the Lena and is in a region of continuous permafrost. The climate exhibits a strong continentality; at Yakutsk the annual mean temperature is $-10.4^{\circ} \mathrm{C}$ and the lowest temperature measured is $-57.1^{\circ} \mathrm{C}$. The mean annual rainfall in Yakutsk is $213 \mathrm{~mm}$ (e.g. Schulze et al., 1999); the 30-year climatological average is $240 \mathrm{~mm}$. The soils in the area consist of fluvial deposits and are classified as cryomorphic dernotaiga solidized soils. Low annual mean rainfall prevents 
podzolization in this area. Crucial is the influence of the permafrost layer, which thaws down to $1.2 \mathrm{~m}$ below the forest floor during the summer and then freezes up again during the autumn and winter. The dominant species in the forests is Cajanderii Larch: Larix cajanderii. The forests are best classified as "middle taiga" or light taiga.

The forest where the measurements were taken lies about $40 \mathrm{~km}$ northeast of the city of Yakutsk, at the Forest station "Spasskaya Pad" (62 $15^{\circ} 18.4^{\prime \prime} \mathrm{N}, 129^{\circ} 37^{\prime} 07.9^{\prime \prime}$ E). The altitude is $220 \mathrm{~m}$ a.s.l. The site is described extensively in Ohta et al. (2001). At the time of measurement the mean stand height was $18 \mathrm{~m}$ and the stand density 840 trees ha ${ }^{-1}$. The average age of the stand is 160 years. The Japanese-Russian team of Ohta et al. (2001) established a scaffolding tower in 1996 of $32 \mathrm{~m}$ high, which was used to obtain the current set of measurements. In 2001 no separate estimates of plant area index (PAI) were available, but the estimates of Ohta et al. (2001) for the leafless canopy of 1.7 and 3.7 for the fully leaved season made by fisheye photography, may serve as a useful reference. It is relevant to note that due to local fire protections, there has not been fire at the site over the last 80 years.

\subsection{Methods}

The eddy correlation instrumentation consisting of a 3-D Gill Solent sonic anemometer (R2), a krypton hygrometer and a LICOR 6262 infrared gas analyser was installed at $34 \mathrm{~m}$ on a telescopic mast, mounted on the micrometeorological tower. This system measured the net ecosystem exchange of $\mathrm{CO}_{2}$ (NEE) and also latent (evaporation), sensible heat and momentum exchange (e.g. Aubinet et al., 2000). The covariances as well as the raw data were stored and post processed using software that corrects for sensor misalignment, frequency loss, sensor separation etc. (Aubinet et al., 2000; Dolman et al., 2002). We also included the angle of attack dependent calibration as proposed by Gash and Dolman (2003) and as described in van der Molen et al. (2004). We used the open path (Krypton) hygrometer to calculate evaporation.

The measurements of NEE were taken in a two-year period, from 14 July 2000 until 1 December 2000 and the next year from 20 April 2001 to 25 September 2001. During the long and extremely cold winter of Siberia we were not able to continue our measurements. Not all data after October fitted our quality criteria, and so these data are not used in the subsequent analysis. Figure 1 shows the degree of energy balance closure for the 2001 data. A regression line gives a slope of 0.88 with an intercept of 26 and an $r^{2}$ of 0.79 (a regression forced through the origin gives a slope of 0.92). The addition of the angle of attack dependent calibration (van der Molen et al., 2004) improved the energy balance closure by $13 \%$. This degree of energy balance closure gives good confidence in the quality of our flux measurements. We suspect that the remaining energy loss is due to a mismatch of the

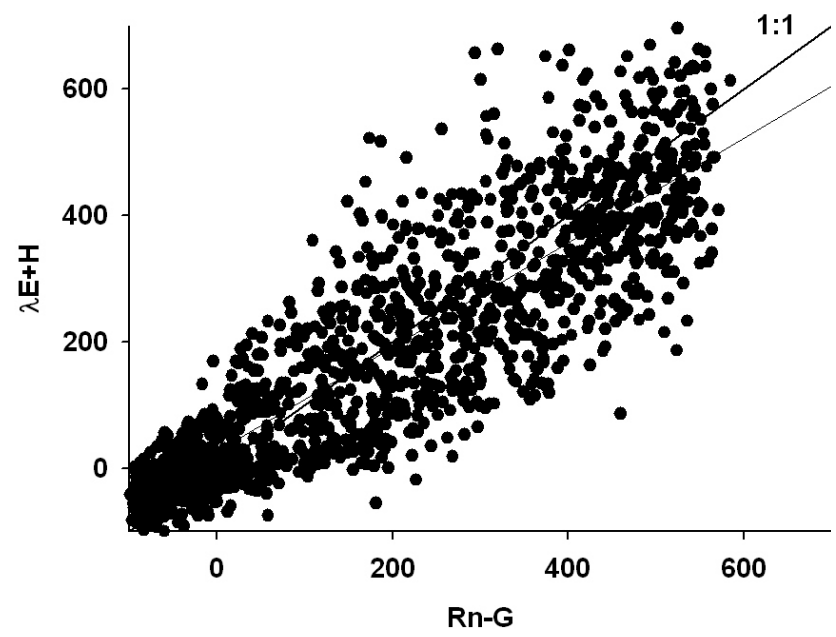

Fig. 1. Energy balance closure test for $30 \mathrm{~min}$ averages of the sum of latent and sensible heat versus net radiation minus soil heat flux. The slope of the line is 0.83 with an intercept of $26 \mathrm{Wm}^{-2}$ and a $r^{2}=0.79$

footprint of the radiative sensors and the eddy correlation instruments. The half hourly values of available energy may also differ from the eddy correlatin fluxes because we did not correct for storage of heat. This effect would be rather small. Spectra (not shown) show good agreement with the classic Kaimal shapes (Kaimal and Finnigan, 1994). We applied no gap filling.

The sonic anemometer also gives readings of temperature and the Krypton and Licor gas analysers also give atmospheric humidity. We used the sonic temperature and the reading from the closed path analyser to obtain values of atmospheric humidity. Net radiation was measured from the four components and taken from the GAME (GEWEX Asian Monsoon Experiment) data CD-ROM (e.g. Ohta et al., 2003).

\section{Results}

\subsection{Net ecosystem exchange of $\mathrm{CO}_{2}$}

Figure 2 gives the seasonal and daily course of the halfhourly eddy correlation measurements for the $\mathrm{CO}_{2}$ flux plotted as contour lines. We show here both the 2001 set as this covers a full seasonal cycle, and the 2000 dataset that started only in July. We concentrate first on the 2001 measurements. From the start of the 2001 measurements (20 April 2001, day 110) until day 144 the forest looses a small amount of carbon by soil respiration (positive NEE). Around day 130 (10 May) there is a sudden increase in respiration. This appears to be primarily related to increased temperatures, stimulating heterotrophic respiration, that drop down again after that day. Interestingly there is also a small peak around day 140 (20 May) when the NEE is positive. We suggest that some of this peak may be related to pre-budding autotrophic respiration, 

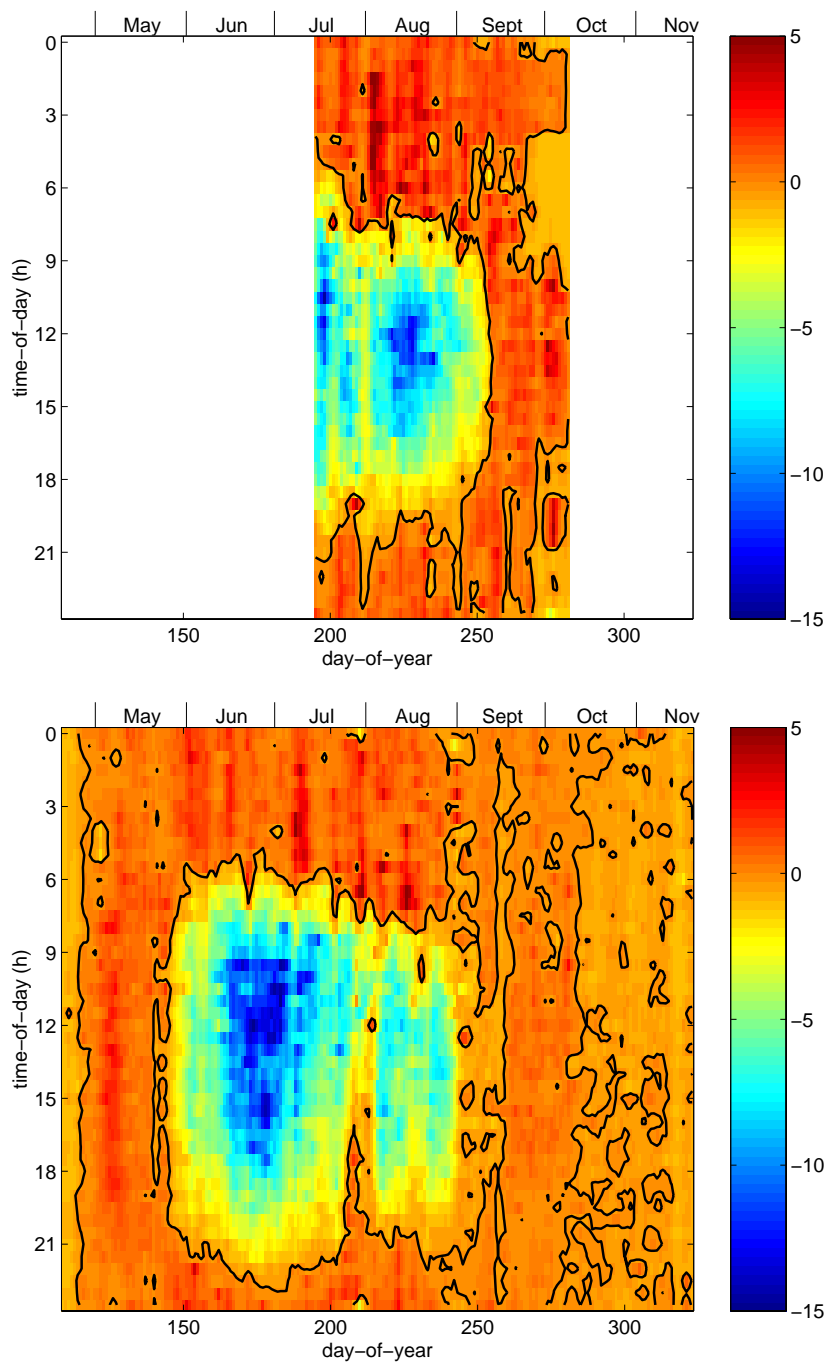

Fig. 2. Diurnal and seasonal $\mathrm{CO}_{2}$ flux for the larch forest at Spasskaya Pad for 2000 (top panel) and 2001 (lower panel). Contour colours indicate the value of $\mathrm{CO}_{2}$ flux $\left(\mu \mathrm{mol} \mathrm{m}^{-2} \mathrm{~s}^{-1}\right)$, the line indicates the zero NEE contour.

caused by the trees starting to produce the needles. From day 144 the forest starts gaining carbon and in only about 3 weeks (day 165) the forest is taking up carbon at maximum rates of about $18 \mu \mathrm{mol} \mathrm{m}^{-2} \mathrm{~s}^{-1}$. After mid-July, around day 200, the uptake decreases in a particularly strong fashion in the afternoon, but recovers somewhat around early August (day 220). After that, there is an almost steady decrease down from about $10 \mu \mathrm{mol} \mathrm{m}^{-2} \mathrm{~s}^{-1}$ towards $0 \mu \mathrm{mol} \mathrm{m}^{-2} \mathrm{~s}^{-1}$ at the end of the season.

Unfortunately we have no measurements in June 2000 due to technical and custom problems that would allow a full seasonal comparison with the 2001 data. However, there is similarity in the early August uptake but difference in the autumnal uptake of 2000 and 2001. The difference is that NEE in 2000 remains slightly longer negative adding a few ex- tra days of uptake to the annual total. Furthermore the peak values of uptake are still at $15 \mu \mathrm{mol} \mathrm{m}{ }^{-2} \mathrm{~s}^{-1}$ while those in 2001 are approaching only $60 \%$ of that value. The similarity between years, however, is remarkable in the sense that in both 2000 and 2001 there appears to be a dip in the uptake around late July, after day 200. The timing of this decline in uptake remains noteworthy, and we will come back to this later in the paper. We cannot, of course, rule out the possibility that the observed similarity in timing is fortuitous, and the result a completely random phenomenon, but we believe there that there may be a realistic interpretation possible. In 2001 there is total of 100 days of negative (uptake) $\mathrm{CO}_{2}$ flux from 26 May to 7 September (days 146-251).

The average diurnal trend for the $\mathrm{CO}_{2}$ flux can also be inferred from Fig. 2. It is evident that only three months contribute to the net seasonal uptake: June, July and August. The highest uptake takes place in June 2001. Comparing the colour and shape of the July 2000 and 2001 curves, it appears that in 2000 the uptake is similar at peak times (about $18 \mu \mathrm{mol} \mathrm{m}^{-2} \mathrm{~s}^{-1}$ ). The July curves are similar up to noon, but after that, NEE starts to drop off sharply in 2001 in comparison to those of 2000. This leads to a lower uptake in July 2001 than in July 2000 (see also Table 1). August 2001 (days 210-240) also shows a substantially lower rate than in 2000, with the previously noted similarity in timing of the decline. The uptake is almost finishing at 15:00 LT. We hypothesize that reductions like this are related to the closing of stomata at high vapour pressure deficits, whereas overall reductions, that show less diurnal variation are caused by soil moisture deficits that occurred in 2001, but not in 2000. This will be discussed later down in the paper. In Fig. 2 these effects show as a gradual weakening from top to bottom following the daily cycle and as a weakening of the high uptake colours from right to the left, as the season progresses.

The other effect that can be observed is the lengthening and shortening of the daylight period during the season. In June the forest uptake starts at 06:00 LT. and continues to 22:00 LT at night, because the night is only $3-4 \mathrm{~h}$ long during June at this latitude.

As suggested by the similarity of the daily patterns in both years, the seasonal uptake also exhibits a clear pattern. This is shown as the mean monthly NEE values in Table 1. On average, the forest looses carbon in April and May, while the uptake is strongest in June (at least in 2001), followed by a small decline in uptake in late July with a further decline in August. In September the larch trees have shed their needles, or photosynthetic activity has ceased, and until the soil gets frozen, the soil and trees continue to respire and loose carbon. In 2000, NEE in July is comparable to the July 2001 values. The overall rates for August and September are considerably lower in 2001 than in 2000.

The eddy correlation method measures the fluxes of heat, water vapor and carbon dioxide through the plain at which the measurements are taken. The measured fluxes are equal to the ecosystem fluxes (the exchange of heat, water and $\mathrm{CO}_{2}$ 
Table 1. Monthly mean NEE and day-time and night-time estimates obtained by assuming a day length lasting of 05:00-21:00 LT at Spasskaya Pad in 2000 and 2001 (all values in $\mu \mathrm{mol} \mathrm{m}^{-2} \mathrm{~s}^{-1}$ ). Night-time $u_{*}$ correction based on $u_{*}<0.4 \mathrm{~ms}^{-1}$.

\begin{tabular}{crrrrrr}
\hline Month & NEE $_{2000}$ & Day2000 $_{2}$ & Night $_{2000}$ & NEE $_{2001}$ & Day2001 $_{2}$ & Night $_{2001}$ \\
\hline April & & & 0.28 & 0.25 & 0.36 & \\
May & & & 0.76 & 0.64 & 1.024 & \\
June & & & -3.21 & -5.62 & 2.09 & \\
July & -2.25 & -4.36 & 2.38 & -1.69 & -4.10 & 3.60 \\
August & -2.08 & -3.66 & 3.66 & -1.19 & -2.63 & 0.98 \\
September & 0.66 & 0.47 & 0.47 & 0.39 & 0.23 & 0.75 \\
October & - & - & & 0.19 & 0.12 & 0.15 \\
\hline
\end{tabular}

between the ecosystem and the air) under conditions that (1) there is no storage of heat, water and $\mathrm{CO}_{2}$ in the air between the level of measurements and the ground or (2) there is no net horizontal flux. Normally these conditions are quite well satisfied in the daytime, when the atmosphere is well mixed, but during the night a stable layer may develop wherein particularly respired $\mathrm{CO}_{2}$ may accumulate. The $\mathrm{CO}_{2}$ thus stored in the profile is not accounted for in the nighttime eddy correlation flux, but may appear in the early morning measurements, when the stored carbon dioxide is flushed out of the profile when the nocturnal boundary layer breaks up. If this happens, the annual total carbon flux is not affected by nighttime storage. There is, however, a problem that is likely to occur if the measurement location is on a slope and cold, $\mathrm{CO}_{2}$ rich air is being drained down the slope. The area around the tower in the Larch forest in the Yakutsk area is rather flat.

We provide further evidence for the validity of the two assumptions mentioned above and we estimate the sensitivity of the annual carbon flux to possible errors. The following methods are used to validate the representativity of the eddy correlation fluxes during night-time conditions.

The relationship between the turbulence intensity as expressed in $u_{*}$ and the night time $\mathrm{CO}_{2}$ flux $\left(f_{\text {night }}\right)$ is analyzed for indications of a reduction in the observed flux under calm, stable conditions. Because the relationship between $u_{*}$ and $F_{\text {night }}$ is disguised by the effect of variations in temperature on the respiration rate, the temperature related variation is removed by normalizing $f_{\text {night }}$ to a reference temperature of $10^{\circ} \mathrm{C}$ using a $Q_{10}$ function derived with observations under turbulent night-time conditions. The function $f_{\text {night }}=R_{0} Q_{10}^{T / 10}$ was fitted to the binned averages, resulting in $R_{o}=0.34 \mu \mathrm{mol} \mathrm{m}^{-2} \mathrm{~s}^{-1}$ and $Q_{10}=3.34$. This relationship was applied to convert $f_{\text {night }}$ to a value at a reference temperature of $10^{\circ} \mathrm{C}$ in order to remove the effect of temperature variations in $f_{\text {night. }}$. The resulting normalized night time carbon dioxide flux as a function of $u_{*}$, indicates that the eddy correlation system increasingly underestimates the ecosystem fluxes at night when $u_{*}$ decreases below $0.4 \mathrm{~m} \mathrm{~s}^{-1}$ although the amount of unexplained variation is quite large (Fig. 3). We suspect this may be a result of the temperature

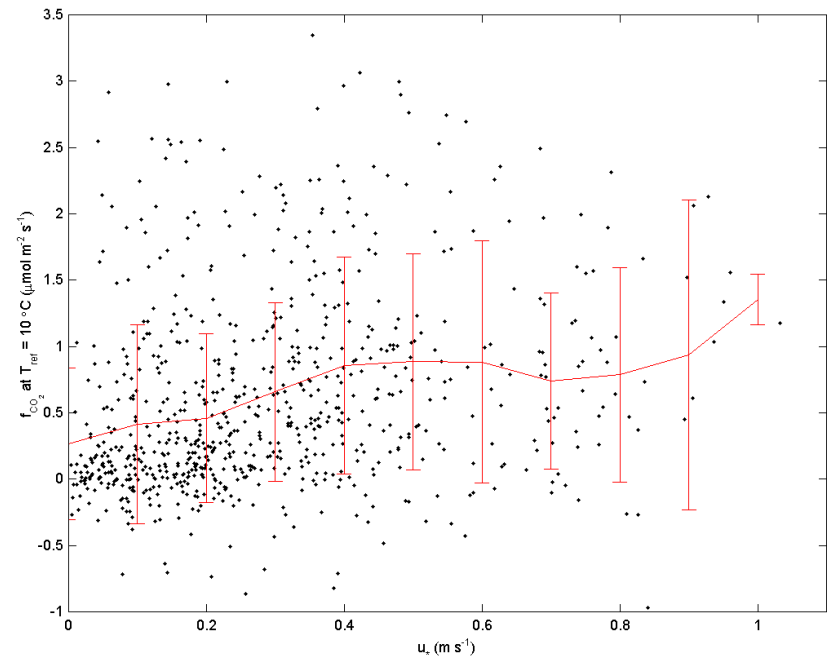

Fig. 3. The night time $\mathrm{CO}_{2}$ flux converted to a reference temperature of $10^{\circ} \mathrm{C}$ as a function of $u_{*}$.

gradient between the height of the eddy correlation system and the ground level, the effect of variations in soil moisture and the depth of the thawed layer in the permafrost. It is important to note that the $u_{*}$ dependency of the night-time flux is quite sensitive to the form of the conversion of $f_{\text {night }}$ to the reference temperature.

At low turbulence intensities $\left(u_{*}<0.4 \mathrm{~m} \mathrm{~s}^{-1}\right)$ mixing is insufficient and carbon dioxide respired from plants and soil accumulates near the ground. This conclusion is in accordance with the observation that the carbon dioxide concentration increases during the night. Consequently there is a potential for underestimation of the eddy correlation fluxes, when horizontal drainage occurs or carbon is flushed nonhomogeneously in the morning.

The diurnal cycles of carbon dioxide flux were inspected for signs of flushing of carbon dioxide stored nocturnally. Close inspection of the diurnal cycle of $\mathrm{CO}_{2}$ uptake in Fig. 2 reveals a slow buildup during the day of the size of the flux, with no noticeable morning flush. In our data averaging this would have shown up, provided morning release of nighttime 
Table 2. Mean monthly latent heat flux (evaporation) at Spasskaya $\mathrm{Pad}$ in 2000 and 2001 (all values in $\mathrm{W} \mathrm{m}^{-2}$ ).

\begin{tabular}{ccc}
\hline Month & $\lambda \mathrm{E}_{2000}$ & $\lambda \mathrm{E}_{2001}$ \\
\hline April & & 8.9 \\
May & & 20.1 \\
June & & 59.9 \\
July & 66.9 & 56.2 \\
August & 50.4 & 21.9 \\
September & 13.6 & 2.6 \\
October & - & 0.6 \\
\hline
\end{tabular}

$\mathrm{CO}_{2}$ is a significant contribution to the total flux. We conclude that there are no indications that nocturnally stored carbon dioxide is suddenly flushed in the morning. The absence of morning flushing either indicates that the carbon dioxide stored at night below the measurement level is gradually mixed into the boundary layer or that it is flushed at a location other than the fetch of our tower. Given the rather homogeneous forest stand at a scale of hundreds of meters around the tower, the latter alternative seems unlikely and we are inclined to assume a gradual mixing in the morning, which appears reasonable given the gradual increase in solar intensity at these Northern latitudes. A gradual release of stored carbon dioxide would increase the confidence in our eddy correlation measurements.

We were able to calculate the amount of carbon dioxide stored below the measuring height from a series of concentration profile measurements taken at the site. These observations of the carbon dioxide profile in the forest were performed in 2001, although infrequently. We have selected a period of 15 days from 31 May 2001 during which observations were available for at least six levels. From these observations, average diurnal cycles were derived for general and calm $\left(u_{*}<0.25 \mathrm{~m} \mathrm{~s}^{-1}\right.$ or $\left.u<2 \mathrm{~m} \mathrm{~s}^{-1}\right)$ (Fig. 4). We note that our cut off value of $0.25 \mathrm{~ms}^{-1}$ is more severe given the 0.4 that is suggested in Fig. 3. Average profiles of carbon dioxide at 00:00, 03:00, 06:00, 09:00, 15:00 and 21:00 LT were obtained in 2001. It becomes evident that the profile is well mixed at daytime and storage of $\mathrm{CO}_{2}$ occurs at night and mainly at ground level and at the level of the highest leaf density $(\sim 13 \mathrm{~m})$. The amount of carbon dioxide stored in these profiles indicates that build-up of storage occurs from about 16:00 LT and has a maximum between 02:00 and 04:00 LT, the time of early sun rise in Yakutsk. The storage flux is associated with changes in the amount of $\mathrm{CO}_{2}$ in the profile. The storage flux is in the order of $1-1.5 \mu \mathrm{mol} \mathrm{m}^{-2} \mathrm{~s}^{-1}$, which appears reasonable at night-time temperatures of $5-19^{\circ} \mathrm{C}$.

We conclude that the storage flux is of similar magnitude as the respiration fluxes that we would expect at this location and from this point of view there is no indication that nocturnally respired carbon dioxide is drained horizontally.

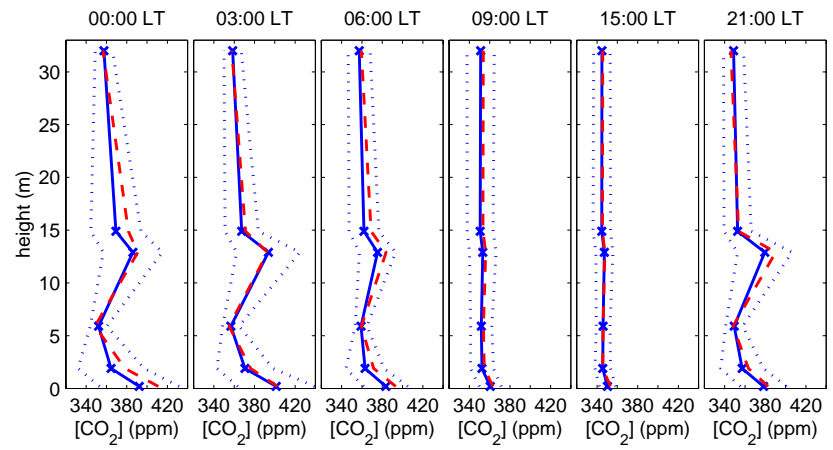

Fig. 4. Average profiles of carbon dioxide concentration between 31 May and 15 June 2001. The solid x-marked line indicates the average concentration, the dotted lines \pm one standard deviation and the dashed line the average concentration during calm conditions $\left(u_{*}<0.25\right.$ or $\left.u<2 \mathrm{~m} \mathrm{~s}^{-1}\right)$.

This again enhances our confidence that the eddy correlation measurements provide a true estimate of the net ecosystem carbon fluxes.

We provide two estimates of the annual NEE on the basis of the preceding analysis. In one method we do not correct for values of low friction velocities. This is in contrast with Fig. 3 that strongly suggests that there is flux loss below values of $0.4 \mathrm{~ms}^{-1}$. Hence we also calculate a monthly and annual NEE that corrects for this flux loss. We note that taking a lower value for the cutoff $\left(0.25 \mathrm{~ms}^{-1}\right)$ does not change this estimate.

Leaving out the $u_{*}$ correction, would increase our estimated annual uptake from 11.64 in $\mathrm{mol} \mathrm{C} \mathrm{m}^{-2} 2001$ to $17.24 \mathrm{~mol} \mathrm{C} \mathrm{m}^{-2}$.

Table 1 shows the differences in total, daytime and nighttime NEE in more detail for the values for which we applied a correction at night-time. When looking at day-time and night-time fluxes separately, it becomes clear that the high rate in June 2001 is primarily caused by high day-time uptake. This is a consistent feature as June is the month with the highest physiological activity of this system. In contrast, the highest night-time fluxes are obtained at the warmer months of July and August.

\subsection{Evaporation and energy balance}

The monthly average evaporation rates are given for 2000 and 2001 in Table 2. The highest evaporation rates for 2000 occur in July (no measurements in June, however) and those of 2001 in June, with little difference between June and July. Evaporation rates in 2000 are consistently higher than in 2001. It is worth noting that the eddy correlation system "sees" both soil and plant evaporation, and there may be some contamination as a result of evaporation from a wet canopy immediately after rainfall. In general however, the measurements system does not yield reliable values during rainfall, so those data were ignored. Overall, the evaporation 

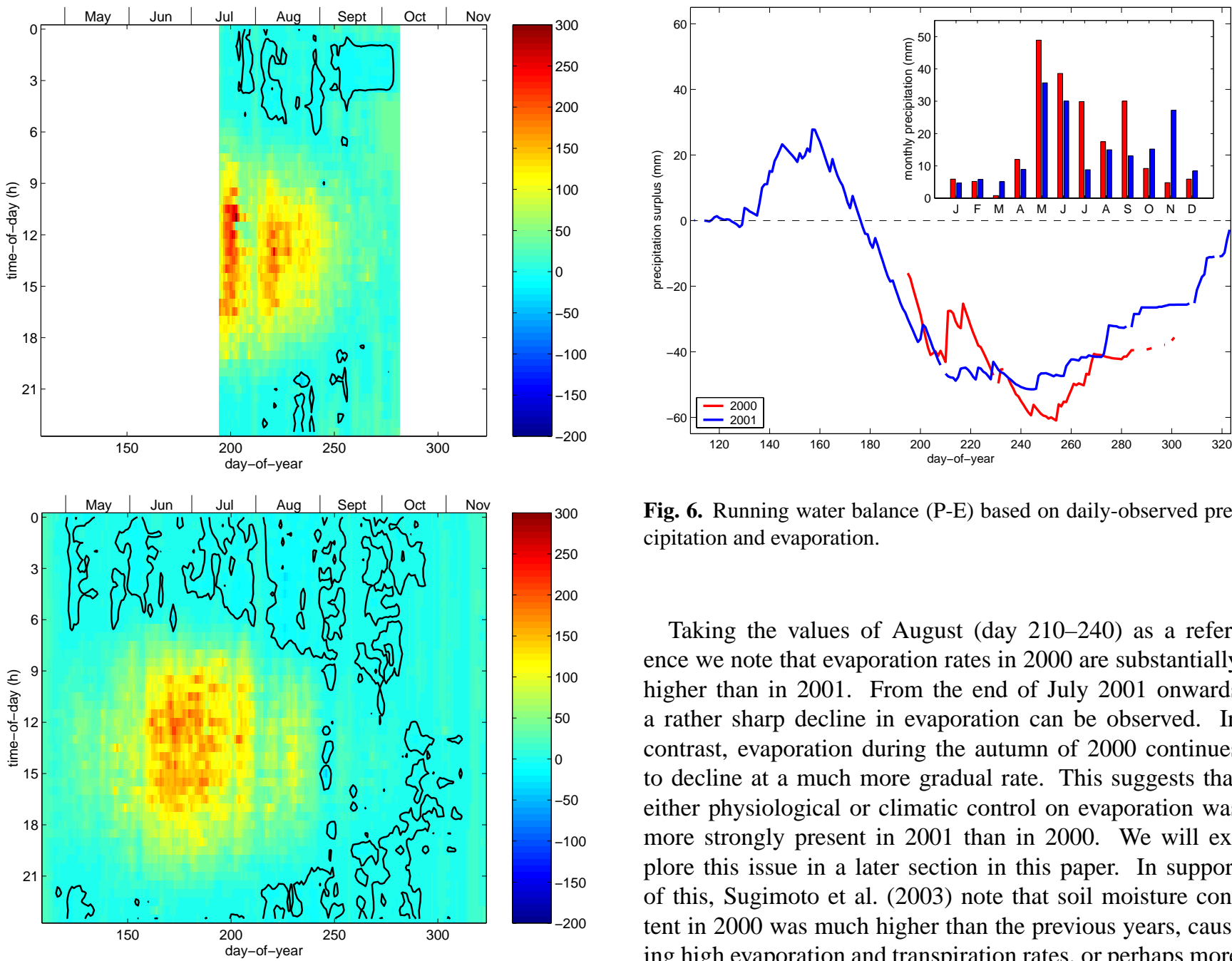

Fig. 6. Running water balance (P-E) based on daily-observed precipitation and evaporation.

Taking the values of August (day 210-240) as a reference we note that evaporation rates in 2000 are substantially higher than in 2001. From the end of July 2001 onwards a rather sharp decline in evaporation can be observed. In contrast, evaporation during the autumn of 2000 continues to decline at a much more gradual rate. This suggests that either physiological or climatic control on evaporation was more strongly present in 2001 than in 2000 . We will explore this issue in a later section in this paper. In support of this, Sugimoto et al. (2003) note that soil moisture content in 2000 was much higher than the previous years, causing high evaporation and transpiration rates, or perhaps more precisely, the presence of enough soil moisture caused evap-

Fig. 5. Diurnal and seasonal course of the latent heat flux above the larch forest at Spasskaya Pad in 2001. Contour colours indicate the magnitude of the latent heat flux $\left(\mathrm{Wm}^{-2}\right)$ and the solid lines indicates the zero latent heat flux contour.

results thus relate primarily to transpiration with a small contribution of soil evaporation on days immediately following rainfall event. We were not able to measure soil evaporation directly. The understorey contribution was also not measured separately, but Ohta et al. (2001) suggest that this may contribute to $35 \%$ of the total evaporation. Given the denseness of the under storey we neglect soil evaporation, and treat the evaporation from the dry understorey and upper storey as a single entity.

Figure 5 shows the diurnal and seasonal course of evaporation (latent heat flux) for 2000 and 2001. In 2001, evaporation is almost zero at the start of the growing season and quickly increases to values of $75 \mathrm{Wm}^{-2}$ later in the season in 2001. Much higher rates were observed in 2000. The rapid increase in latent heat flux coincides with the rapid increase in photosynthetic activity observed in Fig. 2 and is related to the onset of needle growth. oration and NEE to be non-restricted.

To indicate how much soil moisture stress the forest is experiencing, we calculated a running water balance by subtracting the daily measured evaporation from the observed rainfall at Yakutsk airport. Yakutsk airport is about $40 \mathrm{~km}$ away from the measurement site. This is shown in Fig. 6 . The insert shows the monthly rainfall distribution for 2000 and 2001. It is clear from this graph that in the growing season only July generates a large difference in rainfall, with July 2001 the driest month. The largest rainfall deficit approaches $60 \mathrm{~mm}$, towards the end of the growing season. It is worth noting that at this time, the thawing depth approaches $120-140 \mathrm{~cm}$ (Sugimoto et al., 2003). For the loamy sandy soil around the site, Sugimoto et al. (2003) estimate the total soil water content at roughly $400 \mathrm{~mm}$, with some $10 \%$ of that supplied by spring snow melting in 2000 . However, the variation in soil moisture content below $60 \mathrm{~cm}$, roughly half of the thawing depth is small. Once the clay soil is saturated after melting, the top $30-40 \mathrm{~cm}$ soil would contain roughly $100 \mathrm{~mm}$ of water (Sugimoto, et al., 2003). Towards the end of July this water would be depleted by a maximum of $60 \mathrm{~mm}$ 

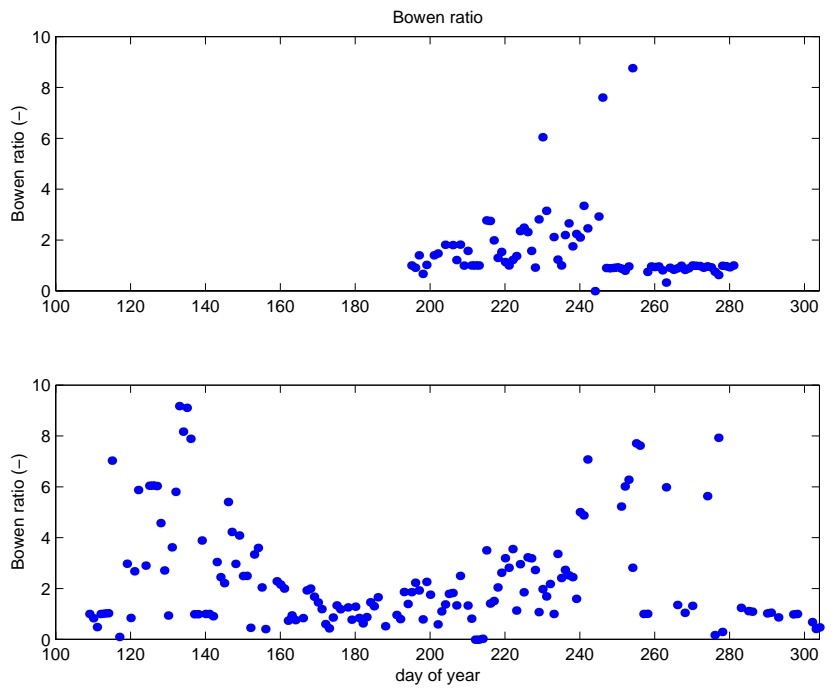

Fig. 7. Bowen ratios for 2000 (top panel) and 2001 (lower panel).

according to Fig. 6 and the remaining moisture would become harder to extract. In both in 2000 and 2001 soil moisture was approaching this limit, but soil moisture was probably not yet severely restricting evaporation and photosynthesis.

Sensible heat flux is the larger term in the energy balance during most of the growing seasons in 2000 and 2001. Bowen ratios (the ratio of sensible heat and latent heat) are generally well above 1 (Fig. 7). In 2001, from days 150 to 250 , the Bowen ratio

$\beta$ is at its lowest value, with values between 1 and 2 . When the forest becomes less active, the Bowen ratio quickly rises to values above 10 . There is a sharp increase in evaporation after day 150 and a sharp stop at day 250 , related to needle growth and senescence, but as can be seen from Figs. 2 and 5 , it is certainly likely that thawing of the top soil layer at the start of the season initiates root activity and that this activity subsequently triggers the growing of the needles. The evaporation early in the growing season is thus probably related to evaporation of melted snow and soil moisture rather than evaporation from the still needle-less canopy. We suspect that the high Bowen ratios before the start of the 2001 season relate to high sensible heat fluxes caused by the capturing of solar radiation at low solar angles by a mostly dark canopy on which the snow cover has decreased, causing an overall low albedo.

Figure 5 also shows that evaporation in the summer months of July and August 2001 is repressed compared to that in the same period in 2000. Evaporation in August 2001 is almost a third of that observed in August 2000. This suggests a severe restriction on evaporation. In June and July 2001 the diurnal trends in evaporation are much more similar than for NEE (Figs. 2 and 5). The observed afternoon drop in evaporation for July 2001 appears smaller than for NEE.
This requires the investigation of possible causes of this drop and an explanation why NEE and evaporation appear to have different responses to limiting environmental factors.

3.3 Surface conductance, specific humidity deficit and the control of NEE and evaporation

The surface conductance, $g_{s}$, is plotted against specific humidity deficit $\delta q$ in Fig. 8b. The surface conductance was obtained by inverting the Penman-Monteith equation allowing for differences in heat and momentum transport and stability (Verma, 1989; Dolman et al., 2002). There is sharp response of the conductance to a change in specific humidity deficit. At high values $\left(\delta q>15 \mathrm{~g} \mathrm{~kg}^{-1}\right)$ the surface conductance is only $30 \%$ of the value at low values. Note that this data includes data at various levels of solar radiation. No attempt is made to separate this into classes of radiation, as there was virtually no difference in the relation obtained, when the data was grouped in four classes of radiation each covering $250 \mathrm{Wm}^{-2}$ (not shown).

In Fig. 9 the diurnal and seasonal course of the specific humidity deficit is plotted for the two years of measurement. Sharp peaks in the specific humidity deficit appear late in the afternoon and are particularly pronounced in both years around days 200-210 (late July). This coincides with the period during which we also observed a dramatic decline in NEE (Fig. 2). In July 2001 the specific humidity deficit is substantially larger than in $2000\left(13 \mathrm{~g} \mathrm{~kg}^{-1}\right.$ in 2001 versus $7 \mathrm{~g} \mathrm{~kg}^{-1}$ ). According to Fig. 8b this would imply an average value of $g_{s}$ of about $2 \mathrm{~mm} \mathrm{~s}^{-1}$ in 2000 and $3 \mathrm{~mm} \mathrm{~s}^{-1}$ in 2001 . This corresponds remarkably well with the observed values. Note that the maximum values of the conductances could be larger, but the binning procedure applied to produce Fig. 8 reduces the overall magnitude.

The reduction in conductance appears to have different effects on the $\mathrm{CO}_{2}$ and evaporation flux. The high specific humidity deficit in July 2001 leads to a sharp drop in $\mathrm{CO}_{2}$ uptake (Table 1), but less so in the evaporation flux, because, although the conductance is reduced by almost $50 \%$, the atmospheric demand through an increase in specific humidity deficit has also increased. In Fig. 8a the response of evaporation is plotted against surface conductance and saturation can be observed to occur after $g_{s}=6 \mathrm{~mm} \mathrm{~s}^{-1}$. In aerodynamically rough vegetation, the evaporation can be approximated by $\lambda E=\left(\rho C_{P} / \gamma\right) g_{s} \times \delta q$ (e.g. Choudhury and Monteith, 1986). This relationship leads to a saturation curve of evaporation for a wide range of specific humidity values (Fig. 8d), as can be understood when a simple negative linear relation between conductance and specific humidity deficit is inserted into the simplified equation for evaporation $\left(g_{s}=g_{\text {smax }}-a \delta q\right.$, where $g_{\text {smax }}$ is the maximum conductance and $a$ a fitting parameter). A reduction in conductance with a corresponding increase in specific humidity deficit does then not lead automatically to a direct change in evaporation, whereas a reduction in $g_{s}$ immediately causes a decrease in $\mathrm{CO}_{2}$ uptake 

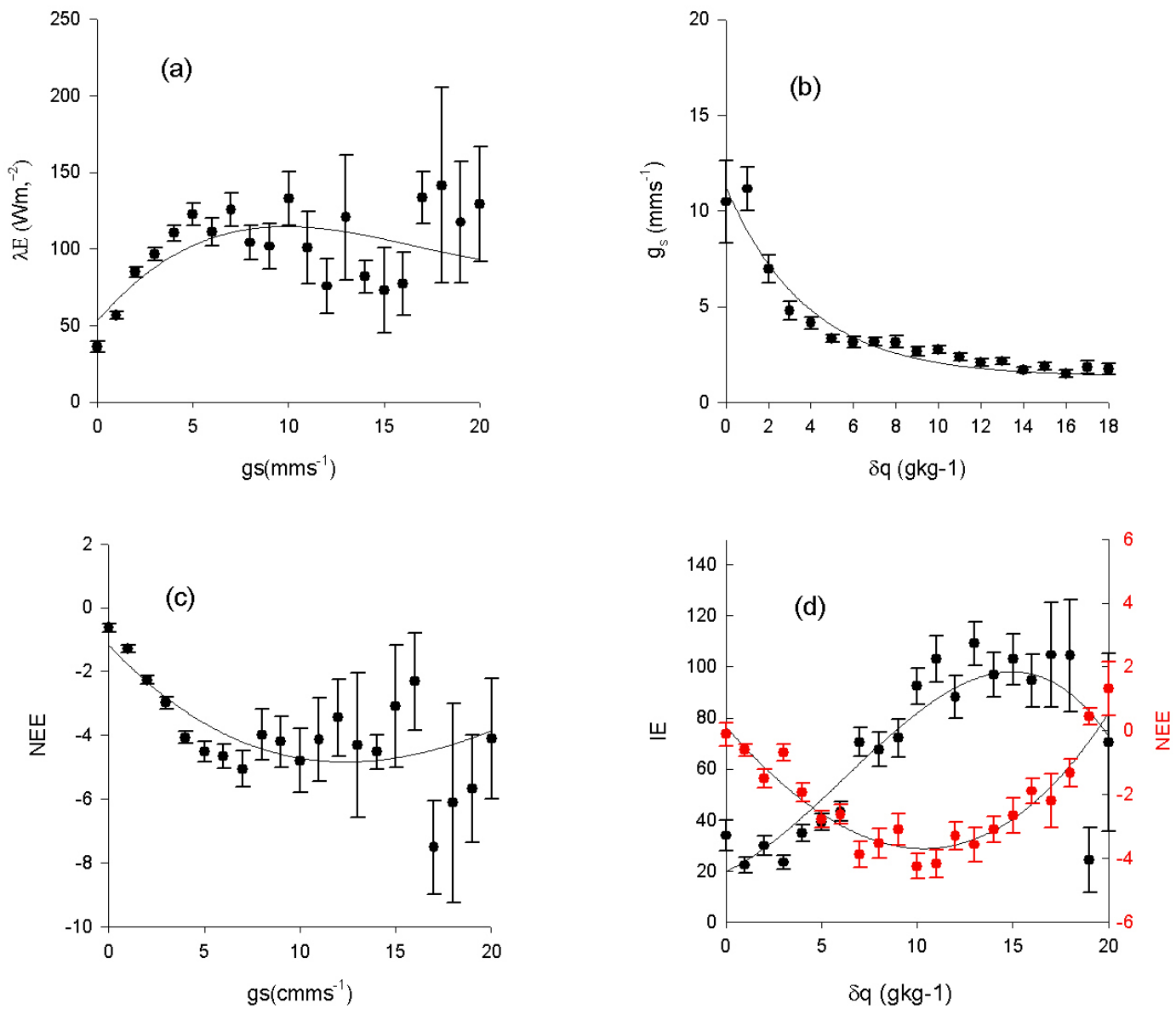

Fig. 8. Relationships between latent heat flux and canopy conductance (a), canopy conductance and specific humidity deficit (b), NEE and canopy conductance (c) and NEE and latent heat flux and specific humidity deficit (d). All values are from 2001 and binned. The curves are drawn to guide the eye. Standard errors are shown to indicate the spread within a binned class and thus depend on both the range and number of values.

(Fig. 8d). If we select the specific humidity values from 10 to $20 \mathrm{~g} \mathrm{~kg}^{-1}$, Fig. $8 \mathrm{~d}$ shows that there is minimal variation in evaporation over this range. This explains why, despite a considerable variation in specific humidity deficit, June and July 2001 have nearly similar evaporation rates. The high values of conductance $\left(>15 \mathrm{mms}^{-1}\right)$ may be contaminated by evaporation from wet canopies or soils or dew. We show them for completeness, but care must taken in their interpretation.

For the same range of specific humidity deficits and corresponding conductances, however, NEE drops from an average value of $4 \mu \mathrm{mol} \mathrm{m}^{-2} \mathrm{~s}^{-1}$ to almost zero. A further interesting phenomenon is that the peak of NEE and evaporation when plotted against specific humidity deficit are shifted with respect to each other. NEE reaches an optimum at lower specific humidity that evaporation. This would be of obvious ecological benefit for a forest with a short growing season, of which a considerable part towards the dry end of the season exhibits very dry atmospheric conditions, that would very rapidly deplete the scarce soil moisture resource in the top soil where most of the active roots are, if such a strong feedback would be absent.

It appears that the higher evaporation values in the summer of 2000 may be explained by the absence of significant atmospheric constraints on the conductance through vapour pressure deficit. The work of Sugimoto et al. (2003) at the same site suggests that soil moisture deficits may not be that restrictive in 2000 as melting of lower permafrost water provides a continuous source of water to the trees (see also above, Sect. 3.2). In 2001 we had no observations of soil moisture.

Lloyd et al. (2002) found the somewhat surprising result that the water use efficiency of central Siberian pine, expressed as their parameter $\gamma$, describing the change of evaporation over a change of photosynthesis, was different for their two years of analysis. In Fig. 10 we plot a similar quantity, but in line with Dolman et al. (2002) we plot the canopy level conductance as a function of net ecosystem exchange 


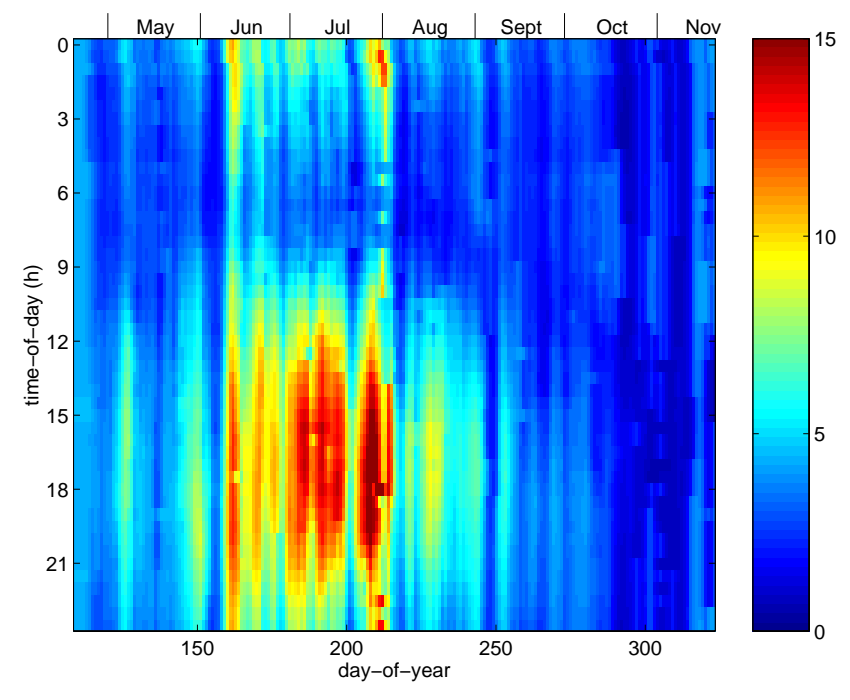

Fig. 9. Diurnal and seasonal course of specific humidity deficit above the larch forest at Spasskaya Pad in 2001. Contour colours indicate the value of specific humidity deficit $\left(\mathrm{g} \mathrm{kg}^{1}\right)$, the contour line indicates a value of $\delta q=0 \mathrm{~g} \mathrm{~kg}^{-1}$.

as expressed by the Ball et al. (1987) linear relationship between these variables once photosynthesis is normalised by internal $\mathrm{CO}_{2}$ concentration and relative humidity. We plot monthly values and although the scatter, particularly towards the high conductance end, is rather large, there appears to be little difference between the growing season months in 2000 and 2001. Particularly values at the high conductance end of the curve may be contaminated by soil evaporation. August 2000 shows a somewhat higher slope, but given the uncertainty associated with the linear regressions, we cannot conclude that this slope is different from the others. The normalised water use efficiency may thus be a fairly constant characteristic of this larch system and not vary substantially between months and years. Variations in the actual water use efficiency (not the normalised values of Fig. 10, that show no effect of atmospheric humidity) occur largely as a result of changing environmental conditions, such as vapour pressure deficits during summer. In fact, the similarity between these relations for several months when relative humidity is used to normalize gives additional evidence for the importance of the specific humidity deficit response on conductance as discussed earlier.

\subsection{Annual carbon sequestration and evaporation of far eastern Siberian Larch}

Total NEE during the growing season of 2001, obtained by summing up daily values, is estimated as 11.64 or $17.24 \mathrm{~mol} \mathrm{C} \mathrm{m}^{-2}$ (139.7 or $208.8 \mathrm{~g} \mathrm{C} \mathrm{m}^{-2}$ ) depending on whether we correct for night time flux loss. We suggest that the lower value that uses the $u_{*}$ correction is more appropriate. We define the growing season as the period when the
NEE is generally positive and assimilation dominates over respiration, but note that there is some uncertainty attached to this definition (Fig. 2). Applying a $u_{*}$ correction method significantly affects the annual NEE estimate. In the appendix we develop an approximation for the respiration that occurs when the permafrost starts freezing up again, from both the top and below. This leads to a small extra amount of respiration of $1.6 \mathrm{~mol} \mathrm{C} \mathrm{m}^{-2}\left(19.2 \mathrm{~g} \mathrm{C} \mathrm{m}^{-2}\right)$. Thus we estimate the total $\mathrm{CO}_{2}$ uptake of this forest in 2001 to be 158.9 or $228 \mathrm{~g} \mathrm{C} \mathrm{m}^{-2} \mathrm{C}\left(\sim 1.6\right.$ or 2.3 ton $\left.\mathrm{Cha}^{-1}\right)$. This assumes, probably correctly that there is no loss in the period JanuaryMarch because of the frozen condition of the soil. There is however evidence from studies in other boreal regions that soil respiration may continue during winter. We were unable to check this for our site, but note that this may further reduce our estimate of annual NEE. Hiyama et al. (2000) estimated a somewhat higher uptake of $210 \mathrm{~g} \mathrm{C} \mathrm{ha}^{-1} \mathrm{yr}^{-1}$, but did not take into account the extra loss due to $\mathrm{CO}_{2}$ trapped in the soil and the overall meteorological conditions may also have been different. Because the peak uptake occurs in June, it appears not reasonable to try to expand our 2000 measurements to a full year. Given the somewhat higher rates in August and September 2000, it is however to be expected that the annual NEE would have been slightly higher in 2000 than in 2001.

The average dry canopy evaporation (transpiration) rate in 2001 is $1.46 \mathrm{~mm} \mathrm{day}^{-1}$ for the growing season. Peak values, in early July are up to $3 \mathrm{~mm}_{\text {day }}{ }^{-1}$, while in September and early April the rates approach zero. Our rates compare well with the $1.25 \mathrm{~mm} \mathrm{day}^{-1}$ found for Scots Pine in the Middle Siberian taiga (Tchebakova et al., 2002) and $1.49 \mathrm{~mm} \mathrm{day}^{-1}$ found by Ohta et al. (2001) for the same forest in Yakutsk. Based on a 100-day growing season this would put the annual evaporation at $146 \mathrm{~mm}_{\text {year }}{ }^{-1}$ and close to the total value estimated by Ohta et al. (2001), of $151 \mathrm{~mm}$. Our values may include some wet canopy evaporation (interception evaporation), however, as there is little rainfall during summer, and data collection in general is poor during rainfall, the impact of including this small, fraction of wet canopy evaporation in our estimates of dry canopy evaporation will be small.

A 100 day growing season may be regarded as the minimum period, based primarily on our $\mathrm{CO}_{2}$ measurements. Expanding it realistically by 20 days (see Figs. 5 and 7) would bring the total dry canopy evaporation close to $175 \mathrm{~mm}$. Ohta et al. (2001) suggested that $15 \%$ of their total evaporation consisted of evaporation of intercepted rainfall. The addition of $32 \mathrm{~mm}$ interception loss would bring the total evaporation close to $200 \mathrm{~mm}$ per year. This is very close to the mean annual rainfall of $213 \mathrm{~mm}$, suggesting there would be little precipitation available for runoff.

\section{Discussion and conclusions}

A first annual estimate of the uptake of East Siberian larch is estimated to be $160 \mathrm{~g} \mathrm{C} \mathrm{m}^{-2} \mathrm{yr}^{-1}$, based on our 

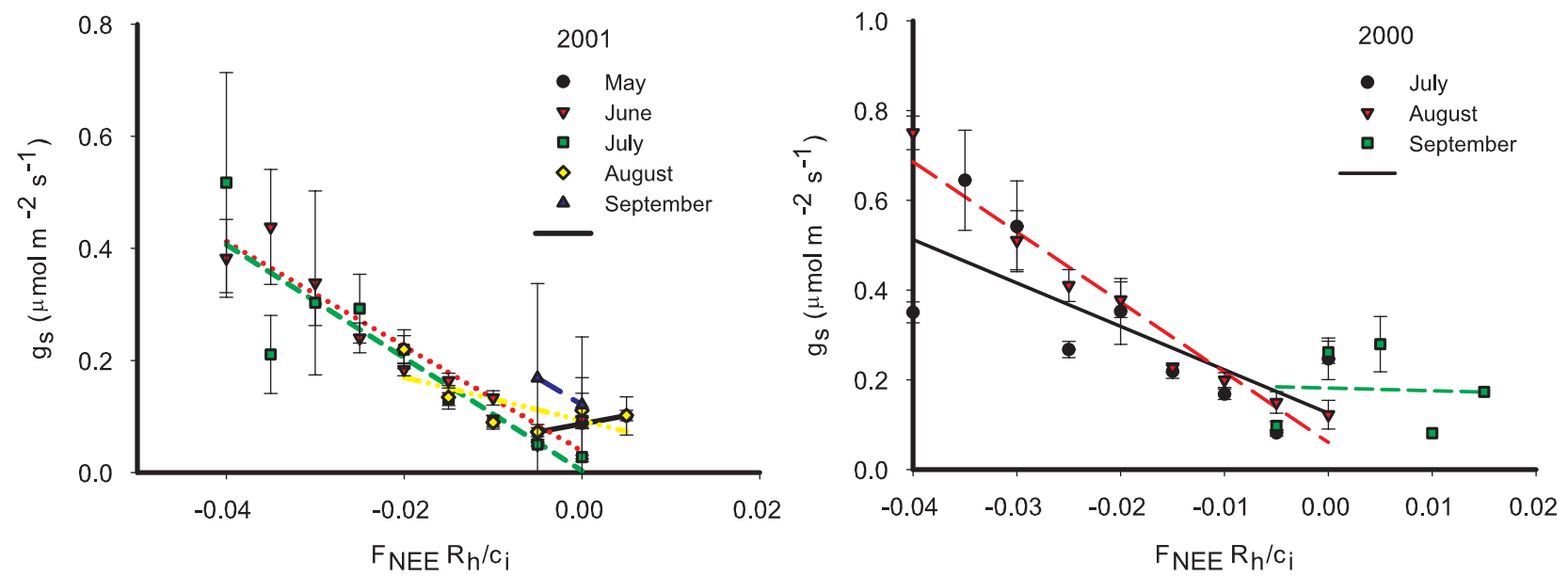

Fig. 10. "Ball Berry" plots for monthly values of conductance and NEE. These illustrate the relations between normalised NEE and canopy conductance as in Ball et al. (1987), but now expressed as a big leaf approximation.

measurements in 2001. Note that this is not the long-term carbon sequestration that is called Net Biome Production. Our estimate is best regarded as Net Ecosystem Production, NEP (Körner, 2003; Dolman et al., 2003). To arrive at the long-term sequestration (NBP), the effects of natural disturbances such as fires would have to be accounted for. Forest fires, harvest and other disturbances will lower NEP substantially. In the longer term it is likely that about $10 \%$ of this net ecosystem sequestration gets locked up in soil carbon as Net Biome Production. According to Shvidenko and Nilson (1994) the total forested area of larch in the Far East of Siberia is $169 \times 10^{9} \mathrm{~m}^{2}$. This would yield an annual sequestration capacity (NEP) of larch in Far East Siberia of 0.27 Pg. This is likely to be an upper estimate and may vary considerable from year to year.

Hollinger et al. (1998) took 14 days of measurements over a larch forest south of Yakutsk and reported very low maximum rates of midday net ecosystem exchange. The values we report here are substantially (a factor 2 ) higher. Both Hollinger et al. (1998) and our work use eddy correlation equipment and obtained good energy balance closure. Assuming that our measurements are correct, there are three possible explanations for this discrepancy. One relates to the possibility that the values obtained from Hollinger et al. (1998)'s series of only 14 days just randomly happened to be on the low side. We cannot completely rule out this possibility, and our year-long measurements suggest that after the peak in June rather sharp declines in uptake may be observed. It would appear however that these are not sufficient to explain the large difference in maximum flux. The second explanation, and to some extent more worrying one, would hold that large spatial differences due to topography and local site conditions may cause such large differences. The fact that these forests occur on permafrost areas where thawing and thermokarst processes may provide rather large differences in site conditions could potentially play a role. If that is the case, the use of single site measurements to represent large areas in global models is even more dangerous than previously assumed. A similar and related explanation would take into account age and density differences in the forest. The Spasskaya Pad forest is in fact older than the Hollinger et al. (1998) forest: 160 versus 125 year. It appears unlikely that this age difference would explain the current differences: one would expect an older forest to take up less carbon. However there is considerable difference in tree density (1000 versus 840 trees per hectare) that may be important. Also, the leaf are index of the Hollinger et al. (1998) forest was estimated at 1.4, considerably lower than the value obtained at Spasskaya Pad by Otha et al. (2001). If this were the main cause, the implication for large scale modelling would be that density and leaf area distribution as related to age and fire frequency would be crucial information.

The results obtained in this study can be compared with other studies on Siberian ecosystems. The overall rates of NEE compare well with those given by Röser et al. (2002) and Lloyd et al. (2002) for Central Siberian pine forests, but are somewhat higher. The most noticeable phenomenon in the present case is the very sharp increase in negative NEE (uptake) after initial needle growth. Our measurements are mostly obtained during the growing season, but the forest can be assumed to be completely dormant for nine months of the year and appears then to suddenly switch to photosynthesis in June. June clearly is the month with the highest uptake, whereas for the Central Siberian forest this appears to be July (Röser et al., 2002).

Our summer rates are high $\left(18 \mu \mathrm{mol} \mathrm{m}^{-2} \mathrm{~s}^{-1}\right)$ : maximum rates quoted by Röser et al. (2001) for West Siberian Betula and two mixed stands are 13,10 and $8 \mu \mathrm{mol} \mathrm{m}^{-2} \mathrm{~s}^{-1}$, respectively. Lloyd et al. (2001) for a pine forest quote maximum median values of $12.5 \mu \mathrm{mol} \mathrm{m}^{-2} \mathrm{~s}^{-1}$, but maximum 
rates are more in agreement with those of us. In the case of the current larch forest Hiyama (2000) quotes maximum uptake rates for July of $15.9 \mu \mathrm{mol} \mathrm{m}^{-2} \mathrm{~s}^{-1}$, comparable to the current values. The high daytime rates rates are further substantiated by independent measurements of photosynthesis in 2003 that show maximum rates at leaf level in July of about $12 \mu \mathrm{mol} \mathrm{m}^{-2} \mathrm{~s}^{-1}$. With a leaf area index of around 2 this would yield maximum photosynthesis rate at canopy level of $24 \mu \mathrm{mol} \mathrm{m}{ }^{-2} \mathrm{~s}^{-1}$. This adds credibility to the present estimates, and suggests that $\mathrm{CO}_{2}$ uptake rates of larch forest in East Siberia at peak times may be higher than those of pine forest in Central Siberia.

The evaporation values are also somewhat higher than previously quoted. The only data that are comparable to those presented in this paper are those of Kelliher et al. (1997) and Ohta et al. (2001), Kelliher et al. (1997) presenting measurements only for a few days in June. These authors suggest that there is little control of surface conductance on evaporation and $\mathrm{CO}_{2}$ exchange. Apart from the fact that theirs is a different site and the results pertain only to a very short period of June 1993, they also show a substantial reduction in conductance and transpiration as a result of increasing vapour pressure deficit. Our results contradict that analysis. Particularly in July 2001 there is marked response in surface conductance but less so in evaporation. Such a response has also been observed by Lloyd et al. (2002). We suggest that the response in transpiration to changes in $g_{s}$ may be masked by the interplay between on the one hand a reduction in conductance and on the other an increase in atmospheric demand. This assumes soil evaporation can be neglected.

The forests of the Far East Siberia survive in an extreme environment, low annual rainfall and extremely low temperatures, possibly complemented by strong nitrogen deficiencies. The precipitation varies considerably between years, but as Sugimoto et al. (2003) have shown, water shortages may not occur even in dry years, as an additional supply of fossil water is available that it can be melted from the lower layers in the active root layer. This has a stabilising effect on transpiration. We suspect that the strong vapour pressure deficit response plays a role in keeping the transpiration rates at a level that is sustainable when this extra source of soil moisture becomes available in the late summer. Continuing to transpire at high rates may cause the forest to senesce too early in the season. This arguably goes at the cost of a decreased carbon uptake, and thus may be a previously unrecognised factor explaining the low growth rates of the forest in addition to the obvious response of growth to low temperatures. However, the surprisingly high C-uptake rates we observed during the summer appear to provide an additional balancing force that ensures that over the short growing season sufficient carbon is still taken up to provide maintenance for the trees. Remarkably, as shown in Fig. 2, the forest appears to be able to recover from a period of low uptake in July, and increases its uptake of carbon later in the season when conditions are again more favourably.
On the basis of our findings we would suggest that an increase in temperature, leading to higher values of the specific humidity deficit would decrease the $\mathrm{CO}_{2}$ uptake of these forest. Although, increases on atmospheric $\mathrm{CO}_{2}$, enhanced precipitation, permafrost melting and an extended growing season may counterbalance such a response to climate change, our analysis indicates that the small current net carbon sequestration capacity of Siberian larch forest is extremely vulnerable to these small climatic changes and may show some quite unexpected behaviour in the future.

\section{Appendix: Calculation of $\mathrm{CO}_{2}$ losses due to respiration trapped soil}

After September the permafrost starts freezing on from below and the topsoil gets frozen from above. This leads to a small layer in the soil at temperatures above zero that can still respire. Observations of concentrations of $\mathrm{CO}_{2}$ (Ivanov, et al., 1995) show indeed very high levels of $\mathrm{CO}_{2}$. The $\mathrm{CO}_{2}$ thus trapped is released when the two freezing layers meet and the soil cracks. Observations of $\mathrm{CO}_{2}$ concentrations in the surface air in December show this as an increase. We can estimate the amount of $\mathrm{CO}_{2}$ lost in this process by assuming a linear growth of the freezing layers over a period of say 75 days from a total soil depth of $1.5 \mathrm{~m}$. This can be expressed as

$F_{\text {nee }}=2 F_{\text {resp }} \int z(t) d t=2 F_{\text {resp }} \int_{\text {day }=0}^{\text {day }=75} 0.75 t-0.005 d t$,

where $F_{\text {nee }}$ is the total flux of $\mathrm{CO}_{2}$ lost by respiration, $F_{\text {resp }}$ the average respiration rate at zero degrees expressed per mol day ${ }^{-1} \mathrm{~m}^{-1}$. Analysis of night-time respiration against air temperature suggest that this is $0.5 \mu \mathrm{mol} \mathrm{m}^{-2} \mathrm{~s}^{-1}$ or $0.0288 \mathrm{~mol} \mathrm{day}^{-1} \mathrm{~m}^{-1}$. The total respiration thus lost would amount to $1.62 \mathrm{~mol} \mathrm{~m}^{-2}$ or $19.44 \mathrm{gm}^{-2} \mathrm{C}$.

Acknowledgements. The Dutch Ministry of Agriculture, Nature Management and fisheries through the PIN-Matra Programme and the European Commission under the Fifth Framework Programme TCOS-Siberia (EVK2-CT-2001-00131), funded part of this study. We thank J. Lloyd and four anonymous reviewers for their perceptive criticism on an earlier version of this manuscript.

Edited by: T. J. Battin 


\section{References}

Aubinet, M., Grelle, A., Ibrom, A., Rannik, Ü., Moncrieff, J., Foken, T., Kowalski, A. S., Martin, P. H., Berbigier, P., Bernhofer, Ch., Clement, R., Elbers, J., Granier, A., Grünwald, T., Morgenstern, K., Pilegaard, K., Rebmann, C., Snijders, W., Valentini, R., and Vesala, T.: Estimates of the annual net carbon and water exchange of forests: The EuroFlux methodology, Adv. Ecol. Res., 30, 113-176, 2000.

Ball, J. T., Woodrow, I. E., and Berry, J. A.: A model predicting stomatal conductance and its contribution to the control of photosynthesis under different environmental conditions, Progress in Photosynthesis Research: Proceedings of the Seventh International Congress on Photosynthesis, edited by: Biggins, J., Providence, Rhode Island, USA, 10-15 August 1986, Martinus Nijhoff Publishers, 4, 221-224, 1987.

Bousquet, P., Ciais, P., Peylin, P., Ramonet, M., and Monfray, P.: Inverse modelling of annual atmospheric $\mathrm{CO}_{2}$ sources and sinks, 1 Method and control inversion, J. Geophys. Res., 104, 26 161$26178,1999$.

Buermann, W., Anderson, B., Tucker, C. J., Dickinson, R. E., Lucht, W., Potter, C. S., and Myneni, R. B.: Interannual covariability in Northern Hemisphere air temperatures and greenness associated with El Niño-Southern Oscillation and the Arctic oscillation, J. Geophys. Res., 108, D13, 4396, doi:10.1029/2002JD002630, 2003.

Choudhury, B. I. and Monteith, J. L.: Implications of stomatal response to saturation deficit for the heat balance of vegetation, Agric. For. Meteorol., 36, 215-225, 1986.

Dixon, R. K., Brown, S., Houghton, R. A., Solomon, A. M., Trexler, M. C., and Wisniewski, J.: Carbon pools and flux of global forest ecosystems, Science, 263, 185-190, 1994.

Dolman, A. J., Moors, E. J., and Elbers, J. A.: Characteristics of the carbon uptake of a mid latitude pine forest on sandy soil, Agric. For. Meteorol., 111, 157-170, 2002.

Dolman, A. J., Schulze, E.-D., and Valentini, R.: Analyzing carbon flux measurements, Science, 30, 916-917, 2003.

Gash, J. H. C. and Dolman, A. J.: Sonic anemometer (co)sine response and flux measurement: I. The potential for (co)sine error to affect sonic anemometer-based flux measurements, Agric. For. Meteorol., 119, 195-207, 2003.

Georgiadi, A. G. and Fukushima, Y.: Water and energy cycle in permafrost regions of Eastern Siberia, GAME publication 17, Research report of IAHS 6, Nagoya, 1999.

Heimann, M.: The Eurosiberian carbonflux project, Tellus B, 54, 417-419, 2002.

Hollinger, D. Y, Kelliher, F. M., Schulze, E.-D., Bauer, G., Arneth, A., Byersb, J. N., Hunt, J. E., McSevenyb, T. M., Kobak, K. I., Milukovae, I., Sogatcheve, A., Tatarinove, F., Varlargine, A., Ziegler, W., and Vygodskayae, N. N.: Forest-atmosphere carbon dioxide exchange in eastern Siberia, Agric. For. Meteorol., 90, 291-306, 1998.

Hiyama, T., Ohta, T., Tanaka, H., and Fukushima, Y.: Flux observations in eastern Siberia, Proceedings of International workshop for advanced flux network and flux evaluation, Sapporo, NIES, 2000 .

Ivanov, B. I., Maximov, T. C. et al.: $\mathrm{CO}_{2}$ emissions by conifers and leaf-bearing forest of Yakutia, Institute for Biological Problems of the Cryolithozone, Yakutsk, 1995.

Kaimal, J. C. and Finnigan, J. J.: Atmospheric Boundary layer flows
Their structure and measurement, Oxford, University Press, 304, 1994.

Kelliher, F. M., Hollinger, D. Y., Schulze, E.-D., Vygodskaya, N. N., Byers, J. N., Hunt, J. E., McSeveny, T. M., Milukova, I., Sogatchev, A., Varlargin, A., Ziegler, W., Arneth, A., and Bauer, G.: Evaporation from an Eastern Siberian larch forest, Agric. For. Meteorol., 85, 135-147, 1997.

Körner, C.: Slow in, Rapid out-Carbon Flux Studies and Kyoto Targets, Science, 300, 1242-1243, 2003.

Lindroth, A., Grelle, A., and Morén, A.-S.: Long-term measurements of boreal forest carbon balance reveal large temperature sensitivity, Global Change Biology, 4, 443-450, 1998.

Lloyd, J., Shibistova, O., Zolotoukhine, D., Kolle, O., Arneth, A., Wirth, C., Styles, L. M., Tchebakova, M., and Schulze, E.-D.: Seasonal and annual variations in the photosynthetic productivity and carbon balance of a central Siberian pine forest, Tellus B, 54, 590-610, 2002.

Lucht, W., Prentice, I. C., Myneni, R. B., Sitch, S., Friedlingstein, P., Cramer, W., Bousquet, P., Buermann, W., and Smith, B.: Climatic control of the high-latitude vegetation greening trend and Pinatubo effect, Science, 296, 1687-1689, 2002.

Ohta, T., Hiyama, T., Tanaka, H., Kuwada, T., Maximov, T. C., Ohata, T., and Fukushima, Y.: Seasonal variation in the energy and water exchanges above and below a larch forest in eastern Siberia, Hydrol. Process., 15, 1459-1476, 2001.

Ohta, T., Hiyama, T., Tanaka, H., Kuwada, T., Maximov, T. C., Ohata, T., and Fukushima, Y.: Hydro-meteorological Data at Larch Forest of Spasskaya Pad. in Dataset for Water and Energy Cycle in Siberia (Version 1), GAME-Siberia and Frontier Observational Research System for Global Change, 2003.

Rödenbeck, C., Houweling, S., Gloor, M., and Heimann, M.: $\mathrm{CO}_{2}$ flux history 1982-2001 inferred from atmospheric data using a global inversion of atmospheric transport, Atmos. Chem. Phys. Discuss., 3, 2575-2659, 2003.

Röser, C., Montagnani, L., Schulze, E.-D., Mollicone, D., Kolle, O., Meroni, D., Papale, D., Marchesini, L. B., Frederici, S., and Valentini, $\mathrm{R}$.: $\mathrm{CO}_{2}$ exchange rates of three differently structured stands in Central Siberia during one vegetation period, Tellus, 54, 5, 631-642, 2002.

Schulze E.-D., Lloyd, J., Kelliher, F. M., Wirth, C., Rebmann, C., Lühker, B., Mund, M., Knohl, A., Milyukova, I. M., Schulze, W., Ziegler, W., Varlagin, A., Sogachev, A. F., Valentini, R., Dore, S., Grigoriev, S., Kolle, O., Panfyorov, M. I., Tchebakova, N., and Vygodskaya, N. N.: Productivity of forests in the Eurosiberian boreal forest region and their potential to act as a carbon sink- a synthesis, Glob. Change Biol., 5, 703-722, 1999.

Serreze, M. C., Walsh, J. E., Chapin III, F. S., Osterkamp, T., Dyurgerov, M., Romanovsky, V., Oechel, W. C., Morison, J., Zhang, T., and Barry, R. G.: Observational Evidence of Recent Change in the Northern High-Latitude Environment, Climatic Change, 46, 159-207, 2000.

Shvidenko, A.: Nilsson: What do we know about the Siberian forests?, Ambio, 23, 396-404, 1994.

Sugimoto, A., Naito, D., Yanagisawa, N., Ichiyanagi, K., Kurita, N., Kubota, J. Kotake, T., Ohata T., Maximov, T. C., and Fedorov A. N.: Characteristics of soil moisture in permafrost observed in East Siberian taiga with stable isotopes of water, Hydrol. Proc., 17, 1073-1092, 2003. 
Tchebakova, N. M., Kolle, O., Zoloutoukhine, D., Arneth, A.,, Styles, J. M., Vygodskaya, N. N., Schulze, E.-D., Shibistova, O., and Lloyd, J.: Inter-annual and seasonal variations of energy and water vapour fluxes above a Pinus Sylvestris forest in the Siberian middle taiga, Tellus, 54, 5, 537-552, 2002.

van der Molen, M. K., Gash, J. H., and Elbers, J. A.: Sonic anemometer (co)sine response and flux measurement, II. The effect of introducing an angle of attack dependent calibration, Agric. For. Meteorol., 122, 95-109, 2004.
Verma, S. B.: Aerodynamic resistances to transfers of heat, mass and momentum, in Estimation of areal evapotranspiration, edited by Black, T. A., Spittlehouse, D. L., Novak, M. D., and Price, D. T., IAHS Publ. 177, Wallingford UK, 13-20, 1989. 